\title{
EXPERIMENTAL STUDY ON RC BeAms Strengthened WITH CARBON AND GLASS FIBER SHEETS
}

\section{Akhrawat Lenwari* and Thaksin Thepchatri}

Department of Civil Engineering,

Faculty of Engineering, Chulalongkorn University,

Bangkok, Thailand 10330

E-mail: *akhrawat.l@chula.ac.th

\section{ABSTRACT}

This study investigates the effects of the two types of fiber sheets, namely, carbon and glass fiber sheets, on the flexural behaviors of reinforced concrete (RC) beams when they are bonded to the tension zones of the beams. A total of eight full-scale beams were tested in the experiments. The flexural strength and stiffness of RC beams were found to increase significantly after the installation of fiber sheets. An analytical model based on the principle of virtual work was developed to predict the load-deflection relationship of the hybrid beams. The paper also highlights the characteristics of debonding problem which limits the effective use of fiber materials. 


\section{Introduction}

Civil engineering applications of fiber-reinforced polymers (FRP) or continuous fiber sheets as the external reinforcements to deficient or deteriorated structures have gained popularity worldwide since their introduction in the mid-1980s [1],[2],[3],[4]. Most applications have been related to flexural strengthening of beams, slabs or columns, shear strengthening of beams or columns, and confinement of columns or column-type elements. The epoxybonded FRP plates or fiber sheets can provide satisfactory solutions to several problems related to conventional steel plates, including the corrosion of the steel plates which brings about the bond deterioration, the difficulty in manipulating heavy steel plates in tight construction sites, the need for scaffolding, and the limitation in available plate lengths for flexural strengthening of long girders, which results in the need for joints. Also, the replacement of conventional steel jackets with FRP wrapped around reinforced concrete (RC) elements provides substantial increase in strength and ductility without much affecting the stiffness [5].

The advantages of fiber materials include their high strength and stiffness, light weight, and good resistance to fatigue and corrosion. Common types of fiber materials are glass, aramid, and carbon fibers [6].

The objective of the study is to investigate the effects of the carbon and glass fibers on the flexural behaviors of RC beams when they are bonded to the tension zones of the beams. The flexural behaviors investigated include the strength, stiffness, ductility, and the failure mode. The principle of virtual work is used to predict the load-deflection relationship of the hybrid beams as well as RC beams.

\section{Analytical Model}

\subsection{Material models}

The compressive stress-strain curve of the concrete is modeled as a parabola from the origin to the maximum compressive stress, $f_{c}^{\prime}$, at a strain of $\varepsilon_{o}=2 f_{c}^{\prime} / E_{c}$ [7], $0 \leq \varepsilon_{c} \leq \varepsilon_{0}$ :

$$
f_{c}=f_{c}^{\prime}\left[2 \frac{\varepsilon_{c}}{\varepsilon_{o}}-\left(\frac{\varepsilon_{c}}{\varepsilon_{o}}\right)^{2}\right]
$$

and as a downward sloping straight line from the strain $\varepsilon_{0}$ to the strain at failure, $0 \leq \varepsilon_{c} \leq 0.004$

$$
f_{c}=f_{c}^{\prime}\left[1-\frac{0.15}{0.004-\varepsilon_{o}}\left(\varepsilon_{c}-\varepsilon_{o}\right)\right]
$$

The model is shown in Figure. 1. The modulus of elasticity is determined from the empirical $\mathrm{ACl}$ formula $\left(f_{c}^{\prime}\right.$ in $\left.\mathrm{MPa}\right)$ :

$$
E_{c}=5000 \sqrt{f_{c}^{\prime}}
$$

The stress-strain curve of steel is assumed to be linear until the yield point is reached and constant thereafter, while that of fiber sheet is linear elastic up to its tensile strength. 


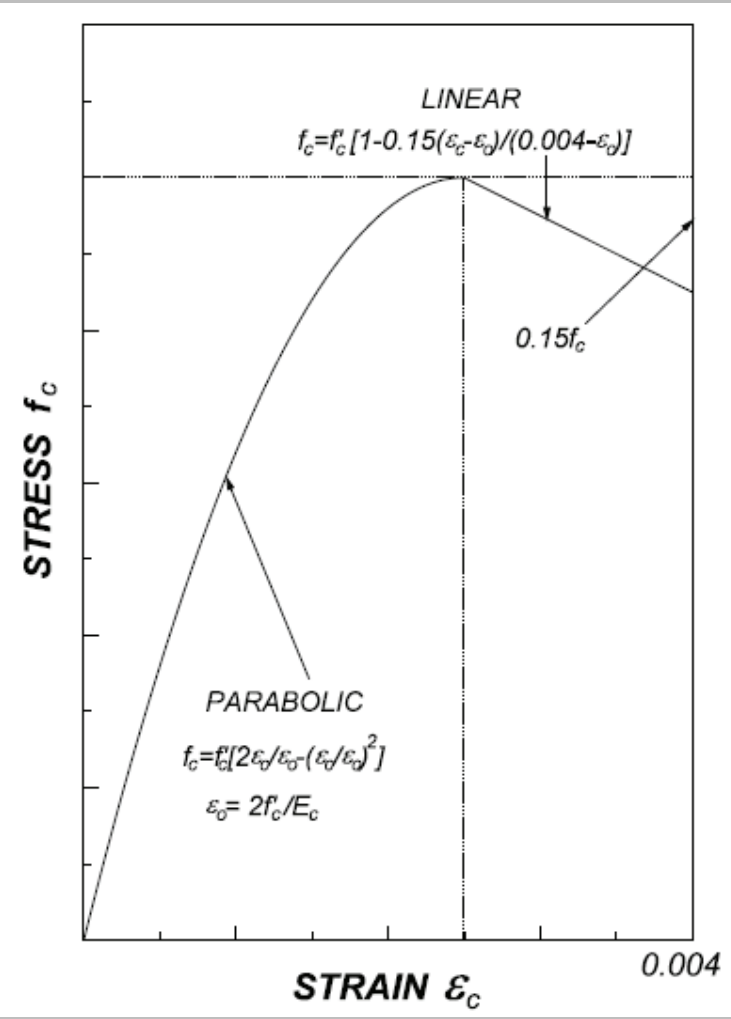

\subsection{Virtual work principle}

To predict the load-deflection relationship of the hybrid beams, the principle of virtual work is applied. Consider any structure deformed by the effect of $n$ external forces, denoted by the vector $\mathbf{P}$. The actual (real) displacements at the same $n$ coordinates are contained in the vector $\mathbf{U}$. The stresses and strains at any point in the structure are elements of the vector $\boldsymbol{\sigma}$ and $\boldsymbol{\varepsilon}$. By setting the external work done to the internal work done, which is the total strain energy, gives

$$
\frac{1}{2} \mathbf{P}^{T} \mathbf{U}=\frac{1}{2} \int_{V} \boldsymbol{\sigma}^{T} \boldsymbol{\varepsilon} d V
$$

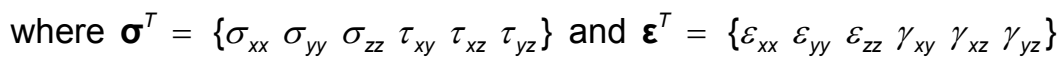

Suppose that before the actual loads and deformations are introduced, the structure was subjected to a system of $m$ virtual forces $\boldsymbol{\delta P}$ that produce internal stresses $\boldsymbol{\delta} \boldsymbol{\sigma}$. By setting the external work done by the actual loads equal to the internal work gives

$$
\frac{1}{2} \mathbf{P}^{T} \mathbf{U}+\delta \mathbf{P}^{T} \mathbf{U}=\frac{1}{2} \int_{V} \boldsymbol{\sigma}^{T} \boldsymbol{\varepsilon} d V+\int_{V} \delta \boldsymbol{\sigma}^{T} \boldsymbol{\varepsilon} d V
$$

Substituting Eq. (4) into Eq. (5),

$$
\delta \mathbf{P}^{T} \mathbf{U}=\int_{V} \delta \boldsymbol{\sigma}^{T} \varepsilon d V
$$

In the unit load method, the system of virtual forces $\mathbf{\delta P}$ is chosen to consist only of a single unit force applied at a specific coordinate where the displacement will be determined.

To predict the midspan deflection of the hybrid beam, a vertical unit virtual force is applied at the midspan. Therefore, the equation for the midspan deflection, $\Delta_{\text {mid }}$, due to bending effect can be written as, 


$$
1 . \Delta_{\text {mid }}=\int_{V} \delta \boldsymbol{\sigma}^{T} \boldsymbol{\varepsilon} d V=\int_{l} \iint_{A}\left(\frac{\delta M \cdot y}{I}\right)(\kappa \cdot y) d A d x=\int_{l} \iint_{A} \frac{\delta M \cdot y^{2}}{I} \cdot \kappa d A d x
$$

Recall that $I=\iint_{A} y^{2} d A$, then

$$
\Delta_{\text {mid }}=\int_{1} \delta M \cdot \kappa d x
$$

If the applied loadings and the hybrid beam are symmetrical,

$$
\Delta_{\text {mid }}=2\left(\int_{0}^{L_{o}} \delta M . \kappa_{l} d x+\int_{L_{o}+L_{d}}^{L / 2} \delta M . \kappa_{l l} d x\right)
$$

where $\delta M$ is the moment distribution due to a unit virtual force. $\kappa_{l}$ and $\kappa_{l l}$ are the curvatures due to the applied loading based on sections without and with fiber sheets, respectively. $L_{o}$ is a distance from the support to the plate end, and $L_{d}$ is a distance for the FRP plate or fiber sheet to develop a composite action, which is assumed to be zero in this study.

To utilize eq. (9), the moment-curvature relationships of the bare $\mathrm{RC}$ and hybrid beam sections have to be established first. The assumptions used to obtain the momentcurvature relationship consist of: 1) linear strain distribution across the (RC or hybrid) beam section, 2) no slip between the fiber sheet and concrete, and 3) no tension force in concrete.

\section{Experimental Program}

A total of eight $15 \times 20 \mathrm{~cm}$ simply supported beams were tested under a four-point loading scheme, as shown in Fig. 2. The span length was $2 \mathrm{~m}$. and the length of fiber sheet was 1.8 $\mathrm{m}$. The beam's cross section was designed to be under-reinforced with the tensile reinforcement ratio $(\rho)$ value of 0.0095 . In all beams, 6-mm-diameter stirrups were provided at a spacing of $80 \mathrm{~mm}$ along the beam span in order to prevent shear failure. Bottom sides of beams were sandblasted to remove dusts and loosening materials before the installation of fiber sheets using epoxy. The curing time for epoxy was at least 2 weeks. A linear variable displacement transducer (LVDT) was installed to measure the beam deflection at midspan.

The material properties are as follows: 1) compressive strength of concrete, $f_{c}^{\prime}$, is $550 \mathrm{MPa}$, 2) yield strength and elastic modulus of steel are $400 \mathrm{MPa}$ and $200 \mathrm{GPa}$, respectively, 3) nominal thickness, tensile strength and elastic modulus of carbon fiber sheet are $0.165 \mathrm{~mm}$., $3550 \mathrm{MPa}$ and $235 \mathrm{GPa}$, respectively, and 4) nominal thickness, tensile strength and elastic modulus of glass fiber sheet are $0.353 \mathrm{~mm}$., $1700 \mathrm{MPa}$ and $71 \mathrm{GPa}$, respectively.

Table 1 shows the strengthening scheme for all test beams. The Beam CB1 and CB2 are the control beams with no fiber sheets. Beams CF1 and CF2 had one and two layers of carbon fiber sheets, respectively, while Beams GF1 and GF2 had one and two layers of glass fiber sheets, respectively. Two specimens with the first layer of carbon fiber sheet and the second layer of glass fiber sheets are Beams CF-GF1 and CF-GF2. All beams were tested to failure and were subjected to periodic unloadings at every $9.81 \mathrm{kN}$ (1 ton), except Beams CB2 and CF-GF2, which were tested under monotonically increasing load until failure.

During the test of Beams CB2, CF1, and GF1, the LVDT was removed when the beam showed a sign of damage; therefore the deflection monitoring was discontinued before failure occurred. 
Figure 2

Test setup for beams

(all dimensions in

millimeter)

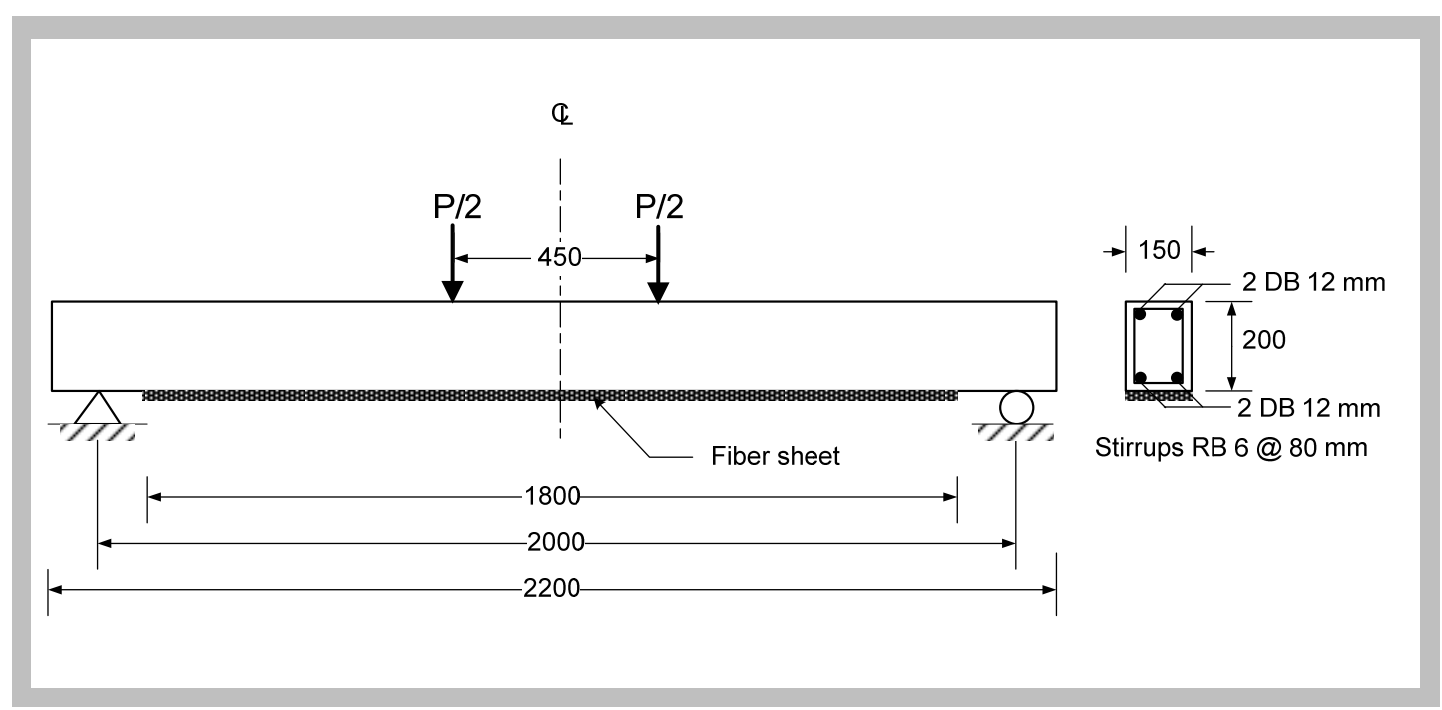

Table 1

Test beams: fiber

type, failure load,

maximum deflection,

and observed failure

mode

\begin{tabular}{|c|c|c|c|c|c|}
\hline Beam no. & Loading type & Fiber type & $\begin{array}{l}\text { Failure load } \\
\qquad(\mathrm{kN})\end{array}$ & $\begin{array}{l}\text { Max. deflection at } \\
\text { midspan (mm) }\end{array}$ & Failure mode \\
\hline CB1 & Periodic unloadings & - & 53.0 & 44.3 & Concrete crushing \\
\hline $\mathrm{CB}^{*}{ }^{*}$ & Monotonic & - & 44.1 & - & Concrete crushing \\
\hline $\mathrm{CF} 1^{*}$ & Periodic unloadings & Carbon, 1 layer & 53.0 & - & Rupture/Debonding \\
\hline GF1* & Periodic unloadings & Glass, 1 layer & 61.8 & - & Delamination \\
\hline CF2 & Periodic unloadings & Carbon, 2 layers & 93.2 & 31.3 & Debonding \\
\hline GF2 & Periodic unloadings & Glass, 2 layers & 97.1 & 36.2 & Debonding \\
\hline CF-GF1 & Periodic unloadings & $\begin{array}{l}\text { Carbon }\left(1^{\text {st }} \text { layer }\right) \\
\text { Glass }\left(2^{\text {nd }} \text { layer }\right)\end{array}$ & 93.2 & 29.8 & Debonding \\
\hline CF-GF2 & Monotonic & $\begin{array}{l}\text { Carbon }\left(1^{\text {st }} \text { layer }\right) \\
\text { Glass }\left(2^{\text {nd }} \text { layer }\right)\end{array}$ & 85.3 & 31.6 & Debonding \\
\hline
\end{tabular}

\section{Test Results and Discussion}

Table 1 summarizes the failure loads, maximum deflections at midspan, and the observed failure modes for all beams. As expected, the control beam CB failed by concrete crushing. The observed failure mode of most hybrid beams was debonding. This failure mode is unfavorable because the tensile strength of fiber sheet is not fully utilized.

From previous researches, possible failure modes in hybrid beams may be grouped into six categories as follows: (a) steel yield and FRP rupture, (b) concrete crushing, (c) shear failure, (d) debond of concrete layer along rebar (steel reinforcement), (e) delamination of FRP, and (f) peeling due to shear crack [8].

Fig. 3 shows the observed failure mode in Beam CF1 with one layer of carbon fiber sheet. The failure mode was a combination of peeling and rupture of fiber sheet at midspan.

The failure in Beam GF1 was the delamination of fiber sheet, as shown in Fig. 4. The most observed failure mode was the peeling with no rupture in the fiber sheets. This failure occurred in Beams GF2, CF-GF1, and CF-GF2. Fig. 5 shows typical failure characteristics observed in Beam CF-GF2.

Finally, the debond of concrete layer along rebar starting at the end of fiber sheets had led to the failure in Beam CF2, as shown in Fig. 6. 


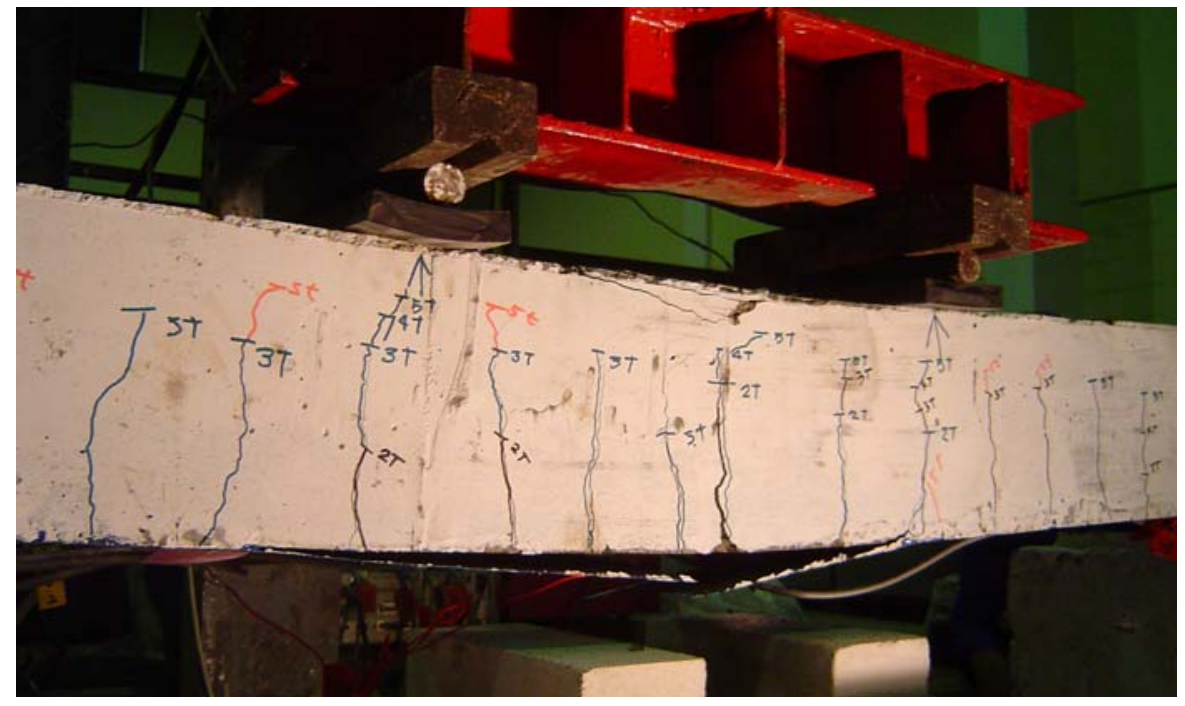

Figure 3

Failure due to peeling

and rupture of fiber

sheet at midspan

(Beam CF1)

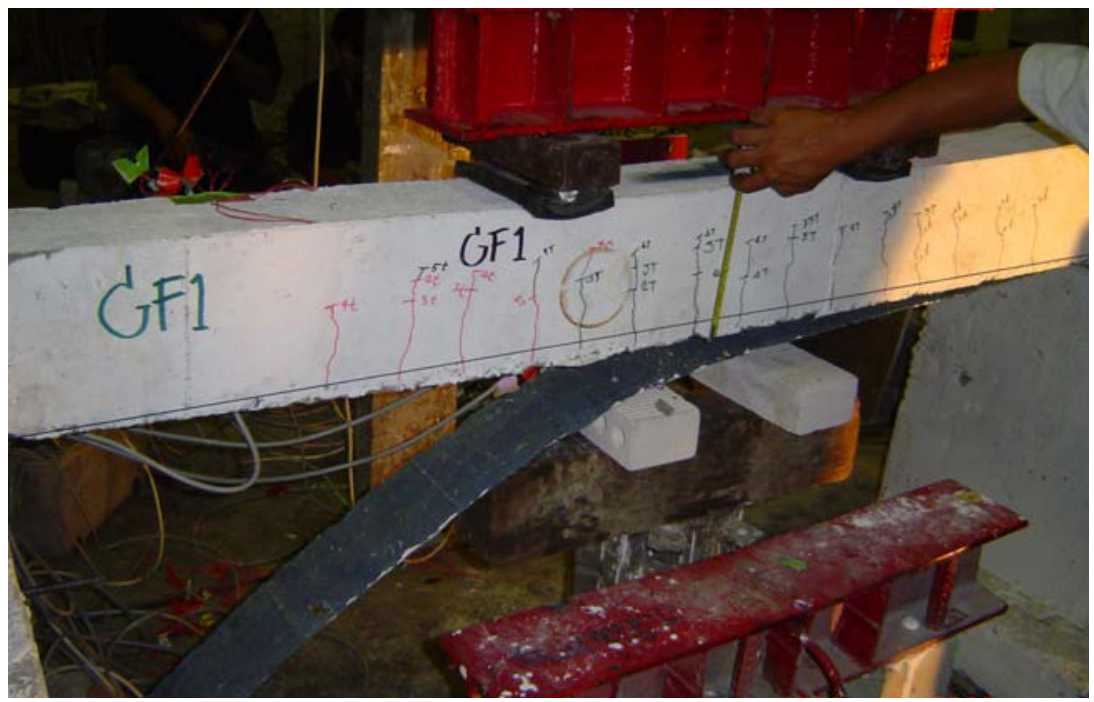

Figure 4

Failure due to

delamination of fiber sheet (Beam GF1)

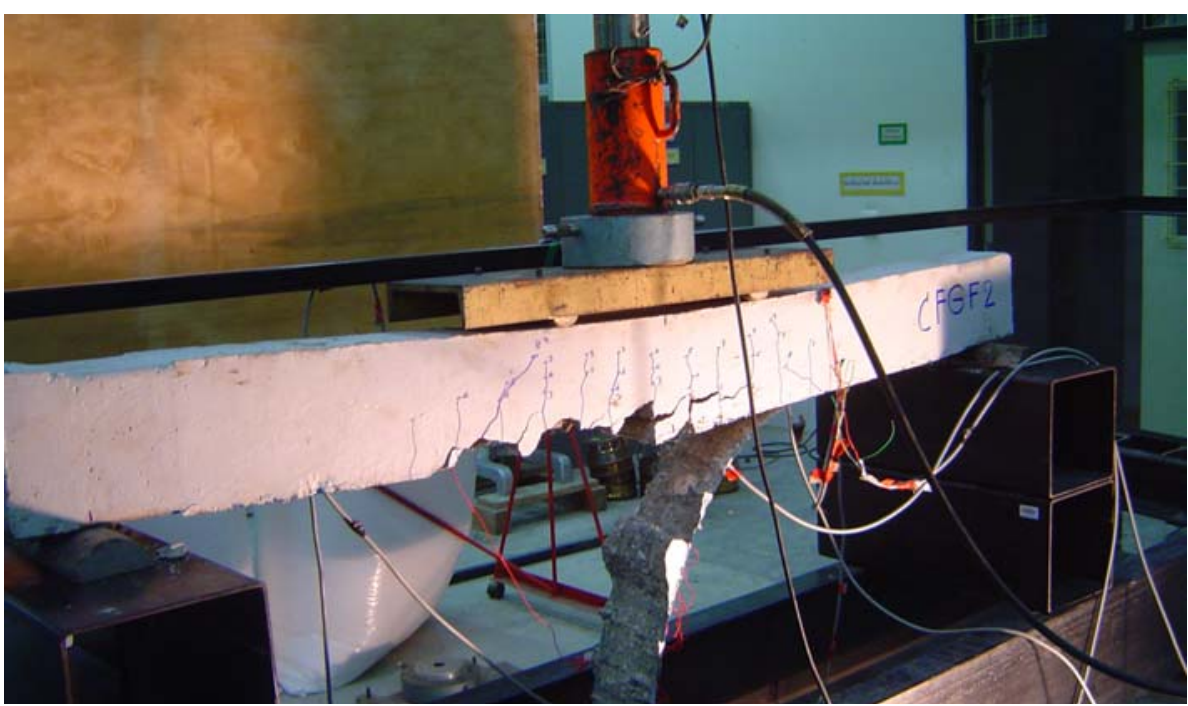

Figure 5

Failure due to peeling of fiber sheets (Beam CF-GF2) 
Figure 6

Failure due to peeling and rupture of fiber sheet at midspan (Beam CF1)

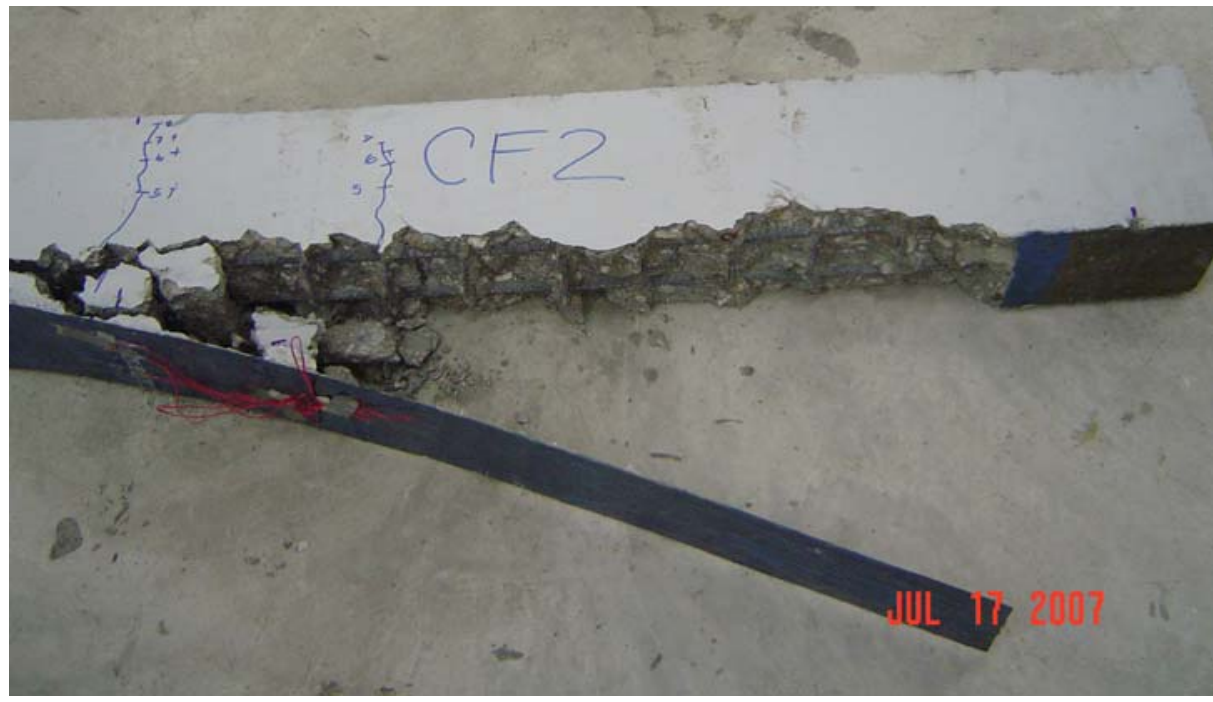

Figs. 7 to 14 plot the relationships between measured load and deflection at midspan of Beams CB1, CB2, CF1, GF1, CF2, GF2, CF-GF1, and CF-GF2, respectively. For comparison purposes, the predicted curves from the virtual work principle are also plotted as dashed lines.

\section{Figure 7}

Load versus midspan deflection of Beam CB1 (no fiber)

\section{Figure 8}

Load versus midspan deflection of Beam CB2 (no fiber, monotonic test)
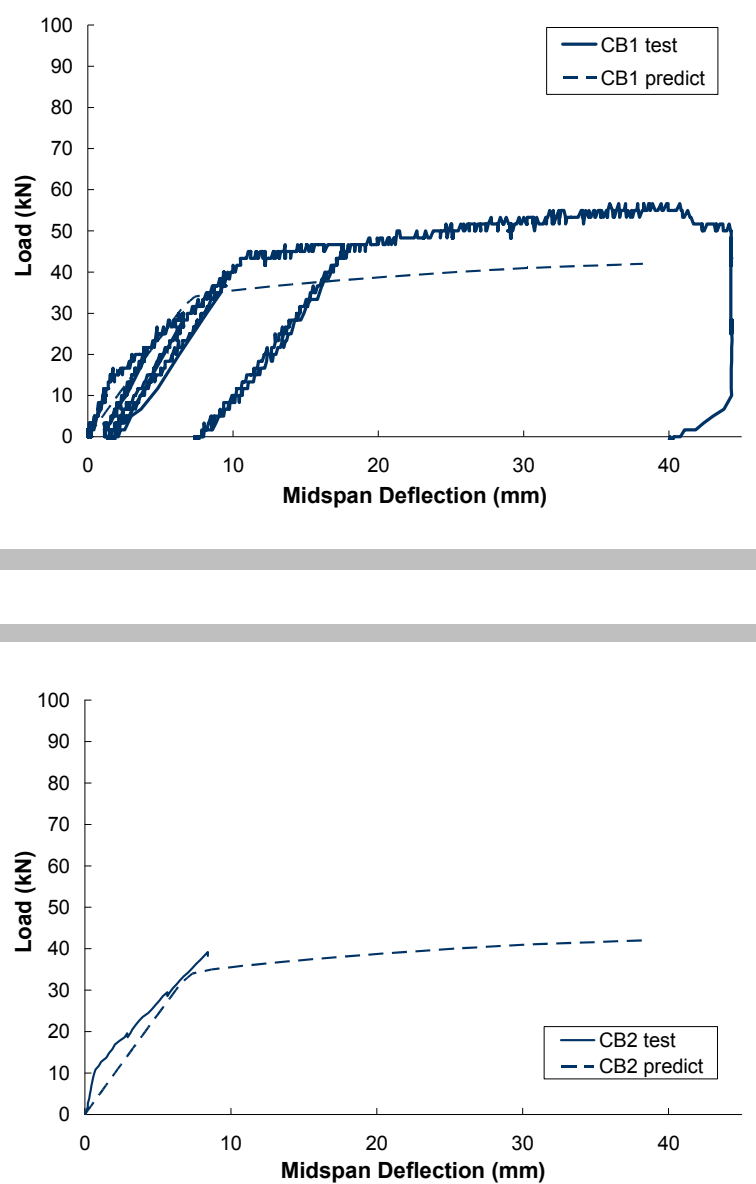

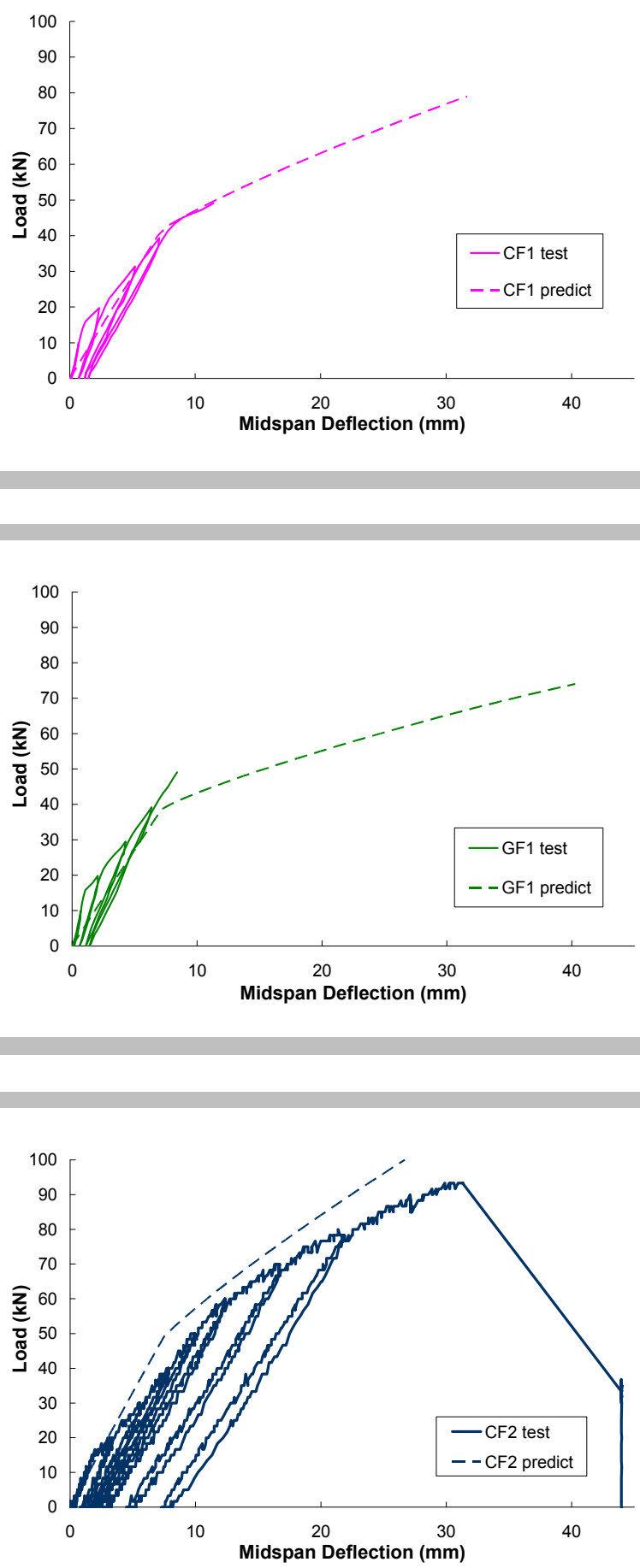

Figure 11

Load versus midspan deflection of Beam

CF2 (2 layers of carbon fiber)

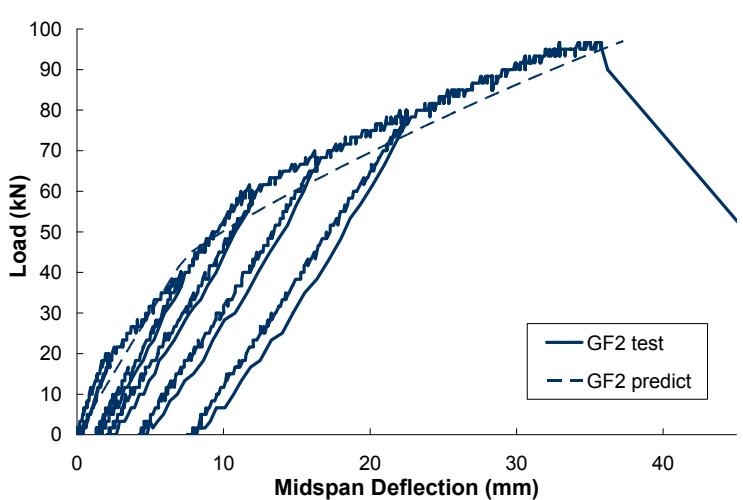

Figure 12

Load versus midspan deflection of Beam GF2 (2 layers of glass fiber) 
Figure 13

Load versus midspan deflection of Beam CF-GF1 (2 layers of carbon and glass fibers)

\section{Figure 14}

Load versus midspan deflection of Beam CF-GF2 (2 layers of carbon and glass fibers, monotonic test)


From the above figures, a reasonable agreement between the test data and the prediction was found; thus indicating the applicability of the virtual work principle. The effects of carbon and glass fiber sheets on the strength and ductility of hybrid beams can be summarized as follows:

1. The stiffness and ultimate load of hybrid beams increased with the number of layers. However, the ultimate load may not increase when the number of layers is greater than two because the effectiveness of fiber sheet is limited by debonding failure.

2. At equal number of layers, the effect of glass fiber on the ultimate load of the beam was more pronounced than carbon fiber. With one layer, the glass fiber sheet increased the ultimate load by $61.8 / 53=1.17(17 \%)$, while two layers increased the ultimate load by $97.1 / 53=1.83(83 \%)$.

3. The ductility of all hybrid beams was lower than the control beam (with no fiber sheets) due to the debonding failure.

4. Unloading at points above the yield load showed significant energy dissipation. However, the reloading stiffness was not significantly dropped from the initial beam stiffness.

5. In monotonic tests (Beams CB2 and CF-GF2), the beams failed at the ultimate loads approximately $85-90 \%$ of those in the periodic unloading tests (Beams CB1 and CFGF1, respectively).

\section{Conclusion}

This study investigates the effects of carbon and glass fiber sheets on the flexural behaviors of RC beams when they are bonded to the tension zones of the beams. The flexural behaviors including the strength, stiffness, ductility, and the failure mode of the beams were investigated by eight tests on full-scale beams. An analytical model based on the principle of virtual work was developed to predict the load-deflection relationship of the hybrid beams.

Debonding failure is a critical issue that limits the effectiveness of the strengthening method using fiber sheets. The research is currently underway to develop an accurate method to predict the debonding failure in the hybrid beams using the stress and energy principles.

\section{ACKNOWLEDGEMENT}

The authors would like to acknowledge Nontri Co. Ltd., Thailand, for the preparation of test beams and the assistance during the experiments. 


\section{REFERENCES}

[1] U. Meier, "Bridge repair with high performance composite materials," Material und Technik, vol. 15, pp. 125-128, 1987. (in German).

[2] F. S. Rostasy, "Bonding of steel and GFRP plates in the area of coupling joints. Talbrucke Kattenbusch.," Federal Institute for Materials Testing, Braunschweig, Research Report No. 3126/1429, 1987. (in German).

[3] M. N. Fardis and H. Khalili, "Concrete encased in fiberglass-reinforced plastic," ACl Journal, vol. 78, pp. 440-446, 1981.

[4] H. Katsumata, Y. Kobatake, and T. Takeda, "A study on strengthening with carbon fiber for earthquake-resistant capacity of existing reinforced concrete columns," in Proceedings of Workshop on Repair and Retrofit of Existing Structures. Tsukuba, Japan: U.S.-Japan Panel on Wind and Seismic Effects, U.S.-Japan Cooperative Program in Natural Resources, pp. 1816-1823, 1987.

[5] E. E. Gdoutos, K. Pilakoutas, and C. A. Rodopoulos, Failure analysis of industrial composite materials: McGraw-Hill, 2000.

[6] ACl Committee 440, ACl 440.2R-02 : Guide for the design and construction of externally bonded FRP systems for strengthening concrete structures.: American Concrete Institute, 2002.

[7] R. Park and T. Paulay, Reinforced concrete structures, 1st ed. New York: John Wiley \& Sons, 1975.

[8] O. Buyukozturk and B. Hearing, "Failure behavior of precracked concrete beams retrofitted with FRP," Journal of Composites for Construction, vol. 2, pp. 138-144, 1998. 